\title{
Effects of Age and Sex on the Pharmacokinetics, Safety, and Tolerability of Oral Desvenlafaxine in Healthy Adults
}

\author{
Alice I Nichols ${ }^{1 *}$, Lyette S Richards ${ }^{2}$, Jessica A Behrle ${ }^{2}$, Joel A Posener ${ }^{2}$, Richard Fruncillo ${ }^{2}$ and Jeffrey Paul ${ }^{2}$ \\ ${ }^{1}$ Pfizer Inc, formerly Wyeth Research, Collegeville, Pennsylvania, USA \\ ${ }^{2}$ Former employee of Wyeth Research, Collegeville, Pennsylvania, USA
}

\begin{abstract}
Background: Desvenlafaxine (administered as desvenlafaxine succinate) is a serotonin-norepinephrine reuptake inhibitor approved for treatment of major depressive disorder. Because it is primarily eliminated unchanged by renal excretion, it is important to characterize the effect of patient factors, such as age and sex that may influence renal clearance.

Methods: The pharmacokinetics, safety, and tolerability of a single oral dose of desvenlafaxine were assessed in healthy adults stratified by age (young, 18-45 years; elderly, 65-75; very old, $>75$ ) and sex in an open-label, inpatient trial.

Results: Desvenlafaxine was generally well tolerated and was slowly absorbed in all age groups. Mean values for peak plasma concentration $\left(C_{\text {max }}\right)$ for women exceeded those of men $(P<0.001)$, and women had a shorter time to $C_{\max }(P=0.011)$. Compared with young participants, mean total area under the plasma concentration-versus-time curve (AUC) and $\mathrm{C}_{\text {max }}$ values were $55 \%$ and $32 \%$ higher in very old participants, respectively. These differences were largely driven by decline in renal function.

Conclusion: There were small to moderate pharmacokinetic differences with oral desvenlafaxine across the age and sex cohorts; however, the magnitude of the differences do not warrant specific dose adjustments based solely on sex or age. The possibility of reduced renal clearance should be considered when determining the dose for patients aged $>75$ years.
\end{abstract}

Keywords: Desvenlafaxine; Pharmacokinetics; Age; Sex; Renal function

\section{Introduction}

Desvenlafaxine is the major active metabolite of the structurally novel antidepressant venlafaxine and is administered clinically as a succinate salt $[1,2]$. Desvenlafaxine is approved for the treatment of major depressive disorder (MDD) [3,4]. Short-term safety, tolerability, and efficacy for the treatment of MDD have been demonstrated for desvenlafaxine in double-blind, randomized, placebo-controlled, MDD trials [5-8].

Desvenlafaxine is chemically unrelated to tricyclic, tetracyclic, or other available antidepressants. It is classified as a serotoninnorepinephrine reuptake inhibitor [1]. In vitro studies show that desvenlafaxine exhibits selective reuptake inhibition of serotonin and norepinephrine, with little inhibition of dopamine reuptake [2]. Desvenlafaxine has virtually no affinity for muscarinic-cholinergic, $\mathrm{H}_{1}$-histaminergic, $\alpha_{1}$-adrenergic, dopamine-2, or opiate $(\mu)$ receptors [1]. Desvenlafaxine concentrations in rat brain and hypothalamus tissue compared with plasma following oral administration of the drug indicate that desvenlafaxine has good penetration into the central nervous system [1].

Randomized, placebo-controlled trials in healthy adults have demonstrated that desvenlafaxine is well tolerated, with linear and doseproportional single-dose pharmacokinetics in a dose range of 100 to $600 \mathrm{mg}$ [9-11]. Additional investigation supports dose-proportionality for single desvenlafaxine doses of 50-200 mg (Data on file, Pfizer Inc, formerly Wyeth Research, Collegeville, PA). At steady-state, multipledose accumulation of desvenlafaxine is linear and predictable from single-dose pharmacokinetics [10]. Exposure to desvenlafaxine after desvenlafaxine administration is not affected by genetic polymorphisms of cytochrome P450 (CYP) 2D6, the primary metabolic pathway for the parent compound. No significant differences were observed between CYP2D6 poor metabolizers and extensive metabolizers in peak plasma concentration $\left(\mathrm{C}_{\max }\right)$, area under the plasma concentration-versus-time curve (AUC), or apparent oral dose clearance $(\mathrm{Cl} / \mathrm{F})[12]$.

The majority of desvenlafaxine is excreted in the urine as unchanged desvenlafaxine (45\%) or as a glucuronide conjugate (19\%) [13]. Desvenlafaxine is metabolized primarily by phase 2 enzymes to form the glucuronide conjugate, and to a lesser extent by the phase 1 enzyme CYP3A4 to form N,O-didesmethylvenlafaxine. Less than 5\% of an administered dose is excreted as $\mathrm{N}, \mathrm{O}$-didesmethylvenlafaxine in the urine [13].

It is well recognized that creatinine clearance $\left(\mathrm{Cl}_{\mathrm{Cr}}\right)$ and glomerular filtration rate (GFR) decline with age, independent of diseases that become increasingly prevalent in the elderly [14-17]. Based on the relative amount of desvenlafaxine excreted unchanged in urine, it is important to characterize the potential for pharmacokinetic changes in patient groups, such as the elderly, that may be more susceptible

*Corresponding author: Alice I Nichols, Pfizer Inc, formerly Wyeth Research, 500 Arcola Rd, Collegeville, PA 19426, USA, Tel: 484-865-8741; Fax: 484-865-9075; E-mail: alice.nichols@pfizer.com

Received December 19, 2012; Accepted March 08, 2013; Published March 14 2013

Citation: Nichols AI, Richards LS, Behrle JA, Posener JA, Fruncillo R, et al. (2013) Effects of Age and Sex on the Pharmacokinetics, Safety, and Tolerability of Oral Desvenlafaxine in Healthy Adults. J Bioequiv Availab 5: 088-094. doi:10.4172/ jbb.1000140

Copyright: @ 2013 Nichols Al, et al. This is an open-access article distributed under the terms of the Creative Commons Attribution License, which permits unrestricted use, distribution, and reproduction in any medium, provided the original author and source are credited. 
to reduced renal function. No apparent age or sex differences were reported in the single-dose pharmacokinetic profile of the parent drug, venlafaxine; a small increase in terminal-phase elimination halflife $\left(t_{1 / 2}\right)$ was observed in elderly patients administered multiple-dose venlafaxine [18]. However, studies assessing the pharmacokinetics and safety profile of desvenlafaxine have not previously been conducted in older populations. Therefore, the purpose of this study was to evaluate the pharmacokinetic profile of desvenlafaxine in healthy men and women stratified by age. The safety and tolerability of multiple-dose desvenlafaxine have been studied over the dose range of 50 to 400 $\mathrm{mg} /$ day in MDD patients [5-8,19]. The recommended therapeutic dose of desvenlafaxine is $50 \mathrm{mg} /$ day; doses greater than $50 \mathrm{mg} /$ day have demonstrated no additional efficacy benefit, whereas rates of discontinuations due to adverse events (AEs) increase at higher doses $[19,20]$. At the time this study was initiated, however, the desvenlafaxine $50-\mathrm{mg} /$ day dose had not been investigated in short-term studies. Consequently, this study used doses of desvenlafaxine that are at the higher end of the dose range.

\section{Materials and Methods}

This was an open-label, inpatient study of a single oral dose of desvenlafaxine. It was conducted at two investigational sites: Wyeth Research Clinical Pharmacology Unit (Philadelphia, PA) and SFBC International (Miami, FL). Providing oversight and approval for the study protocols were the Methodist Hospital Institutional Review Board (Philadelphia, PA) and the LeeCoast Institutional Review Board (Fort Myers, FL). The study schedule consisted of screening (day -21 to -2 ) and prestudy (day -1$)$ periods to assess the eligibility and health status of participants, followed by a 4-day study period (days 1 to 4 ). The primary end point was the effect of age and sex on the pharmacokinetics of a single dose of desvenlafaxine.

\section{Study participants}

Participants eligible to enroll were healthy men and women aged 18 to 45 years (young), 65 to 75 years (elderly), and $>75$ years (very old) meeting inclusion criteria at screening: nonsmoker/light smoker; age-appropriate normal $\mathrm{Cl}_{\mathrm{Cr}}$; body mass index 18 to $30 \mathrm{~kg} / \mathrm{m}^{2}$; body weight $\geq 50 \mathrm{~kg}$; and a high probability of compliance. Health state was determined by the investigator based on history/examination, clinical laboratory test results, vital signs, and 12-lead electrocardiogram (ECG). Elderly and very old groups could enroll with a well-managed chronic illness. Participants were excluded for presence of acute disease state within 7 days of study day 1 ; significant unstable or uncontrolled organ/system diseases; conditions interfering with desvenlafaxine pharmacokinetics; positive orthostatic test; clinical deviation from normal limits on history/examination, clinical laboratory tests, vital signs, or ECG. All participants provided written informed consent before screening.

\section{Treatment and procedures}

A single oral dose of desvenlafaxine (200 or $300 \mathrm{mg}$; obtained from Wyeth Pharmaceuticals which was acquired by Pfizer in October 2009) was administered to each study subject on study day 1 , approximately 30 min after a medium-fat breakfast. After the first 10 study participants completed dose administration, the protocol was changed from 300 to $200 \mathrm{mg}$ because of orthostatic decreases in blood pressure or supine increases in blood pressure in five of seven elderly and very old study participants.

Predose (before $-2 \mathrm{~h}$ to hour 0 ) and postdose $(0.5,1,2,4,6,8,12,24$,
$36,48,60$, and $72 \mathrm{~h}$ ) venous blood samples ( $10 \mathrm{ml}$ each) were collected from each study subject in heparinized tubes to measure desvenlafaxine concentrations. Pharmacokinetic samples were collected at these times with graduated time windows for sample collection. Urine samples were also obtained before dosing ( -12 to $0 \mathrm{~h}$ ) and after dosing ( 0 to 4 , 4 to 8,8 to 12,12 to 24,24 to 48 , and 48 to 72 h). Two 25 -ml aliquots were retained.

\section{Bioanalytical methodology}

Plasma and urine desvenlafaxine assays were performed by Bioassay Laboratory, Inc (Houston TX).

Plasma desvenlafaxine levels: Plasma desvenlafaxine concentrations were determined in the study samples with a validated high-performance liquid chromatography (HPLC) method with fluorescence detection using propranolol hydrochloride as an internal standard. Eight standard concentrations were used for the desvenlafaxine calibration curves; all accepted runs had $r$-values of 0.998156 or better for the calibration standard curves. The interday precision (coefficient of variation $[\mathrm{CV}]$ ) was $5.0242 \%$ or better, and the accuracy ranged from 97.1112 to $104.8520 \%$. Two sets of quality control samples (concentrations: 15, 60, and $300 \mathrm{ng} / \mathrm{ml}$ ) were assayed with each run. Interday precision (CV) for the quality control samples was $5.6736 \%$ or better, and the accuracy ranged from 98.9492 to $99.7581 \%$.

Plasma desvenlafaxine was quantitated using a liquid extraction procedure. A $1.00-\mathrm{ml}$ aliquot of each calibration curve standard, quality control sample, and study sample was mixed with $0.60 \mathrm{ml}$ of working internal standard solution $(1,000 \mathrm{ng} / \mathrm{ml})$ and $0.20 \mathrm{ml}$ of saturated sodium borate solution. After vortexing, the sample was extracted with $6.00 \mathrm{ml}$ of ethyl ether and shaken at high speed. Following centrifuging, the ether layer was separated and extracted with $0.30 \mathrm{ml}$ of $0.01 \mathrm{~N}$ hydrochloric acid solution. After centrifuging, the upper organic layer was discarded and the residual ether was evaporated at $40^{\circ} \mathrm{C}$ under a gentle stream of air. To the acid layer, $50.0 \mu$ of mobile phase was added and a 50.0- $\mu$ l aliquot was injected onto an HPLC system. The HPLC system was equipped with Shimadzu RF-535 fluorescence detector (Columbia, MD; excitation wavelength: $230 \mathrm{~nm}$, emission wavelength: $300 \mathrm{~nm}$ ), Waters 717 autosampler (Milford, MA), and Spherisorb CN analytical column (Waters; $25 \mathrm{~cm} \times 4.6 \mathrm{~mm}, 5$ micron with in-line precolumn filter). The lower limit of quantitation for the assay was $5.0 \mathrm{ng} / \mathrm{ml}$, and the upper limit of quantitation was $500 \mathrm{ng} / \mathrm{ml}$.

Urine desvenlafaxine levels: Desvenlafaxine concentrations were assessed in urine samples by the HPLC method with UV detection. WY-46,071-1 (Wyeth Research, Pearl River, NY) was used as the internal standard. Seven standard concentrations were used for the desvenlafaxine calibration curves. All accepted runs had r-values of 0.996831 or better for the desvenlafaxine calibration standard curves, and the interday precision (CV) was $9.1451 \%$ or better, with accuracy ranging from 93.2680 to $103.9640 \%$. The interday precision (CV) for the quality control samples was $23.2952 \%$ or better and the accuracy ranged from 87.4000 to $101.5667 \%$.

The analyte was quantitated using a liquid-liquid extraction procedure. A $0.10-\mathrm{ml}$ aliquot of each calibration curve standard, quality control sample, and study sample was mixed with $1.00 \mathrm{ml}$ of working internal standard solution $(800 \mathrm{ng} / \mathrm{ml})$ and $0.20 \mathrm{ml}$ of saturated sodium tetraborate solution. The sample was vortexed, then extracted with 5.00 $\mathrm{ml}$ of ethyl ether and shaken at high speed. Following centrifuging, the ether layer was separated and extracted with $0.30 \mathrm{ml}$ of $0.01 \mathrm{~N}$ 
hydrochloric acid solutions. After shaking and centrifuging, the upper organic layer was discarded and the residual ether was evaporated at $40^{\circ} \mathrm{C}$ under a gentle stream of air. To the acid layer, $50.0 \mu \mathrm{l}$ of mobile phase was added and a 50.0- $\mu$ l aliquot was injected onto an HPLC system equipped with a Shimadzu LC-9A pump (Columbia, MD), Waters 717 auto sampler, a UV detector (Spectro Monitor 3200; 229 $\mathrm{nm})$, and Supelcosil LC-8-DB analytical column $(15 \mathrm{~cm} \times 4.6 \mathrm{~mm}$ ID; $5 \mu \mathrm{m}$ particle size) with an inline precolumn filter. The lower limit of quantitation for desvenlafaxine in urine in the analysis was $0.10 \mu \mathrm{g} / \mathrm{ml}$ and the upper limit of quantitation was $10 \mu \mathrm{g} / \mathrm{ml}$.

Desvenlafaxine concentration data for both plasma and urine were acquired by and integrated on a Millennium 32 Chromatography Manager Software System (version 4.00; Waters). The slopes, intercepts, and correlation coefficients were determined by least squares linear regression analysis using the ratios of drug/internal standard peak heights of calibration curve standards. For plasma, the weighting factor of $1 / x$ (1/concentration) was used in the calculation of linear regression line. The weighting factor of $1 / y$ (1/response) was used in the calculation of linear regression line for urine. All the unknowns and the quality control samples were calculated by the Millennium data capture system.

\section{Pharmacokinetic analysis}

Desvenlafaxine plasma concentration data were analyzed for each subject using empirical, model-independent methods. $C_{\max }$ and $\mathrm{t}_{\max }$ were taken directly from observed data, and $\mathrm{t}_{1 / 2}$ was calculated as $\mathrm{t}_{1 / 2}=0.693 / \lambda_{\mathrm{z}}$, where $\lambda_{\mathrm{z}}$ is the terminal-phase disposition rate constant. The area under the single-dose plasma concentration-versus-time curve $\left(\mathrm{AUC}_{\mathrm{T}}\right)$ truncated at the last measurable concentration at time $\mathrm{T}\left(C_{\mathrm{T}}\right)$ was calculated using the linear-trapezoidal rule for increasing concentrations and the log-trapezoidal rule for decreasing concentrations. The terminal-phase elimination rate $\left(\lambda_{z}\right)$ was estimated using the log-linear regression of the last three or more plasma concentrations determined to be in the log-linear elimination phase by visual inspection. Total AUC was calculated as the sum of $\mathrm{AUC}_{\mathrm{T}}$ and $C_{\mathrm{T}} / \lambda_{\mathrm{r}}$. $\mathrm{Cl} / \mathrm{F}$ was calculated as dose/AUC. $\mathrm{Cl}_{\mathrm{R}}$ was calculated as $\mathrm{A}_{\mathrm{e}} /$ AUC, where the numerator represented the amount of desvenlafaxine excreted in urine. $\mathrm{Cl}_{\mathrm{Cr}}$ was estimated from serum creatinine $\left(\mathrm{sC}_{\mathrm{r}}\right)$ using the formula:

$$
\mathrm{Cl}_{\text {Cr male }}(\mathrm{ml} / \mathrm{min})=\frac{(140-\text { age }[\text { years }]) \cdot \text { weight }(\mathrm{kg})}{72 . \mathrm{SC}_{\mathrm{r}}(\mathrm{mg} / \mathrm{dl})}
$$

for males and:

$$
\mathrm{Cl}_{\text {Cr female }}(\mathrm{ml} / \mathrm{min})=\mathrm{Cl}_{\text {Cr male }} .0 .85 \text { for females [21]. }
$$

Safety measurements were analyzed from spontaneous reports of AEs and scheduled evaluations (physical examinations, vital signs, orthostatic evaluation, clinical laboratory tests, and ECG). Predose and serial postdose day 1 measurements of vital signs (e.g., orthostatic blood pressure, pulse), clinical laboratory parameters, and 12-lead ECG were performed. Vital signs and 12-lead ECG were measured each study day. An AE was defined as any untoward, undesired, unplanned clinical event in the form of signs, symptoms, disease, or laboratory or physiological observations occurring with study drug regardless of causal relationship. TEAEs were AEs not present at baseline or events present at baseline that worsened in the treatment period or $<72 \mathrm{~h}$ after dose administration.

\section{Statistical analysis}

All tests of hypotheses were two-sided with significance defined as a level of 0.05 . The dose-normalized plasma concentrations of desvenlafaxine at each sampling time, the dose-normalized pharmacokinetic parameters of desvenlafaxine, and the $A_{e}$ were compared among the six age/sex cohorts using a two-factor analysis of variance with factors for sex, age group, and the interaction between sex and age group. Values for desvenlafaxine plasma concentrations, $\mathrm{C}_{\max }, \mathrm{AUC}$, and $\mathrm{AUC}_{\mathrm{T}}$ were normalized to the $200 \mathrm{mg}$ dose before performing statistical comparisons. All mean values for pharmacokinetic parameters cited in the text are geometric means, unless otherwise stated. Safety parameters (vital signs, ECGs, routine laboratory tests) were analyzed using summary statistics without formal comparisons.

\section{Results}

Forty-eight healthy participants (24 men and 24 women) were enrolled and completed the study; all 48 were included in the intentto-treat and safety populations (Table 1 ). The majority of participants were white $(35 / 48 ; 73 \%)$, ranged in age from 23 to 83 years, and ranged in weight from 45.4 to $108.8 \mathrm{~kg}$. Within each age group (young, aged $18-45$ years $[n=16]$; elderly, aged $65-75$ years $[n=15]$; and very old, aged $>75$ years $[n=17])$, women generally weighed less than men. Where applicable, the demographic and baseline characteristics of age/ sex cohorts were balanced across doses (200 and $300 \mathrm{mg}$ ) except for the men in the young group, among whom those receiving the 200 mg dose were more likely to be younger than their cohorts and the majority were nonwhite.

\section{Pharmacokinetic and pharmacodynamic parameters}

Desvenlafaxine was absorbed in all age/sex cohorts with geometric mean time to peak plasma concentration $\left(\mathrm{t}_{\max }\right)$ ranging from 5.7 to $9.3 \mathrm{~h}$ after oral postprandial administration of 200 or $300 \mathrm{mg}$ (Table 2). Geometric mean AUC ranged from 8,713 to $14,899 \mathrm{ng} \cdot \mathrm{h} / \mathrm{ml}$, and geometric mean $\mathrm{C}_{\max }$ ranged from 402 to $678 \mathrm{ng} / \mathrm{ml}$. Women had significantly higher mean $\mathrm{C}_{\max }(18 \%-37 \%, \mathrm{P}<0.001)$ and slightly, but significantly, shorter mean $t_{\max }(\mathrm{P}=0.011)$ compared with men within each age group. Higher mean AUC (6\%-17\%) and weight-normalized mean $\mathrm{Cl} / \mathrm{F}$ (4\%-15\%) were also seen in women.

Mean AUC, $\mathrm{C}_{\max }$, and weight-normalized mean $\mathrm{Cl} / \mathrm{F}$ showed small to moderate, but statistically significant, changes with age (all $\mathrm{P} \leq$ 0.001; Figure 1). AUC and $\mathrm{C}_{\max }$ both increased with age. Mean AUC of desvenlafaxine was approximately $55 \%$ higher in the very old group than the young group, rising approximately $32 \%$ from the young to the elderly group and by an additional $18 \%$ from the elderly to the very old group. Mean $\mathrm{C}_{\max }$ was approximately $32 \%$ higher in the very old group than the young group. The difference in mean $\mathrm{C}_{\max }$ between the young and elderly groups was small. The mean $\mathrm{Cl} / \mathrm{F}$ of desvenlafaxine decreased with age. This parameter was approximately $27 \%$ and $47 \%$ lower in the elderly and very old groups, respectively, than in the young group. The interaction of age and sex was not statistically significant for any of the parameters.

Approximately 32 to $40 \%$ of the administered dose of desvenlafaxine was recovered unchanged in the urine in the six age/sex cohorts, with no significant difference in recovery among cohorts. Mean renal clearance $\left(\mathrm{Cl}_{\mathrm{R}}\right)$ of desvenlafaxine was $33 \%$ lower in the very old group than the young group. Within age/sex cohorts, $\mathrm{Cl}_{\mathrm{Cr}}$ values were generally similar and, especially in the older age/sex cohorts, paralleled the decline in $\mathrm{Cl}_{\mathrm{R}}$ 
Citation: Nichols Al, Richards LS, Behrle JA, Posener JA, Fruncillo R, et al. (2013) Effects of Age and Sex on the Pharmacokinetics, Safety, and Tolerability of Oral Desvenlafaxine in Healthy Adults. J Bioequiv Availab 5: 088-094. doi:10.4172/jbb.1000140

\begin{tabular}{|c|c|c|c|c|c|c|c|c|c|c|}
\hline \multirow[b]{3}{*}{ Characteristic } & \multicolumn{6}{|c|}{ Desvenlafaxine 200-mg dose } & \multicolumn{4}{|c|}{ Desvenlafaxine $300-\mathrm{mg}$ dose } \\
\hline & \multicolumn{2}{|c|}{$\begin{array}{c}\text { Young } \\
\text { (18-45 years) }\end{array}$} & \multicolumn{2}{|c|}{$\begin{array}{c}\text { Elderly } \\
\text { (65-75 years) }\end{array}$} & \multicolumn{2}{|c|}{$\begin{array}{l}\text { Very old } \\
\text { (>75 years) }\end{array}$} & \multirow{2}{*}{$\begin{array}{c}\text { Young }(18- \\
45 \text { years) } \\
\text { Men } \\
(n=3)\end{array}$} & \multicolumn{2}{|c|}{$\begin{array}{c}\text { Elderly } \\
\text { (65-75 years) }\end{array}$} & \multirow{2}{*}{\begin{tabular}{|c|}
$\begin{array}{c}\text { Very old } \\
(>75 \text { years })\end{array}$ \\
Men \\
$(n=2)$
\end{tabular}} \\
\hline & $\begin{array}{l}\text { Men } \\
(n=5)\end{array}$ & $\begin{array}{c}\text { Women } \\
(n=8)\end{array}$ & $\begin{array}{l}\text { Men } \\
(n=4)\end{array}$ & $\begin{array}{c}\text { Women } \\
(n=6)\end{array}$ & $\begin{array}{l}\text { Men } \\
(n=7)\end{array}$ & $\begin{array}{c}\text { Women } \\
(n=8)\end{array}$ & & $\begin{array}{l}\text { Men } \\
(n=3)\end{array}$ & $\begin{array}{c}\text { Women } \\
(n=2)\end{array}$ & \\
\hline \multicolumn{11}{|l|}{ Age, years } \\
\hline Mean (SD) & $29.6(7.1)$ & $38.0(5.1)$ & $68.8(3.6)$ & $68.8(2.7)$ & $76.9(1.2)$ & $77.9(2.4)$ & $37.7(5.5)$ & $71.7(1.2)$ & $73.0(0.0)$ & $82.0(1.4)$ \\
\hline $\begin{array}{l}\text { Minimum, } \\
\text { maximum }\end{array}$ & $23.0,39.0$ & $29.0,44.0$ & $66.0,74.0$ & $66.0,72.0$ & $76.0,79.0$ & $75.0,81.0$ & $32.0,43.0$ & $71.0,73.0$ & $73.0,73.0$ & $81.0,83.0$ \\
\hline \multicolumn{11}{|l|}{ Race, n (\%) } \\
\hline Black & $3(60)$ & $1(13)$ & & & & & & & & \\
\hline Other & $1(20)$ & $1(13)$ & $1(25)$ & $5(83)$ & & $1(13)$ & & & & \\
\hline White & $1(20)$ & $6(75)$ & $3(75)$ & $1(17)$ & $7(100)$ & $7(88)$ & $3(100)$ & $3(100)$ & $2(100)$ & $2(100)$ \\
\hline \multicolumn{11}{|l|}{ Height, cm } \\
\hline Mean (SD) & $178.5(5.7)$ & $157.3(7.5)$ & $165.6(3.8)$ & $158.8(7.5)$ & $170.3(5.0)$ & $157.0(6.4)$ & $183.8(9.4)$ & $177.8(12.0)$ & $159.0(1.2)$ & $167.7(2.8)$ \\
\hline $\begin{array}{l}\text { Minimum, } \\
\text { maximum }\end{array}$ & $170.0,183.5$ & $140.0,165.0$ & $160.0,168.0$ & $147.0,168.0$ & $165.0,180.1$ & $145.0,165.0$ & $172.9,189.4$ & $169.1,191.5$ & $158.1,159.8$ & $165.7,169.7$ \\
\hline \multicolumn{11}{|l|}{ Weight, kg } \\
\hline Mean (SD) & $86.8(11.1)$ & $62.9(10.3)$ & $69.9(5.7)$ & $67.3(9.2)$ & $77.6(13.2)$ & $63.0(7.3)$ & $85.5(9.8)$ & 89.7 (17.6) & $57.2(6.5)$ & $77.4(14.9)$ \\
\hline $\begin{array}{l}\text { Minimum, } \\
\text { maximum }\end{array}$ & $73.8,100.2$ & $45.4,76.4$ & $62.8,75.9$ & $56.4,78.2$ & $58.6,91.8$ & $49.1,71.4$ & $74.8,94.1$ & 74.2, 108.8 & $52.6,61.8$ & $66.8,87.9$ \\
\hline
\end{tabular}

Table 1: Demographics and baseline characteristics of study participants by age group and sex.

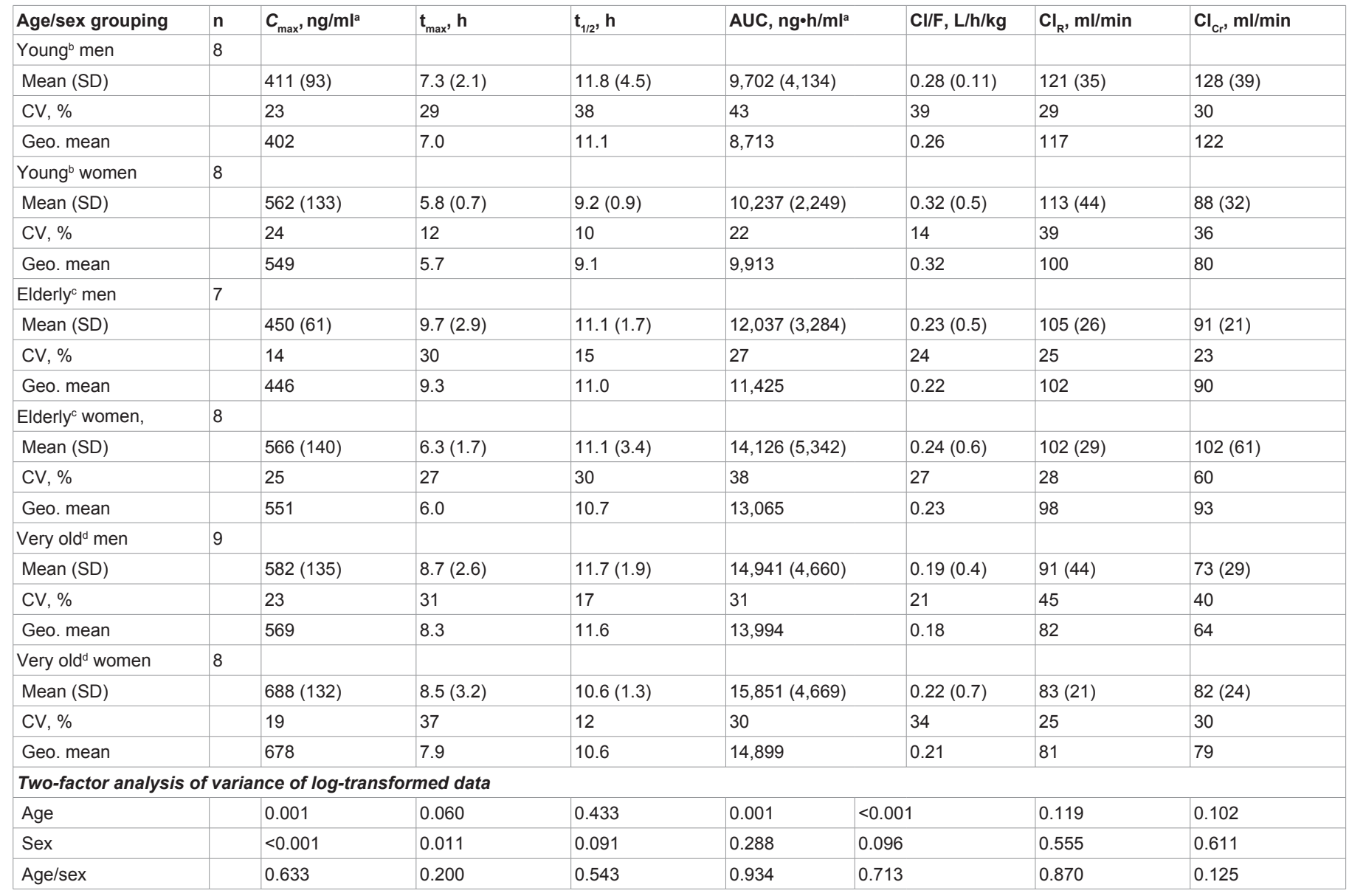

${ }^{\mathrm{a}} \mathrm{C}_{\max }$ and AUC were normalized to a common 200-mg dose.

bYoung, 18-45 years.

cElderly, 65-75 years.

'Very old, $>75$ years.

$\mathrm{AUC}$, total area under plasma concentration-versus-time curve; $\mathrm{Cl}_{\mathrm{Cr}}$, creatinine clearance; $\mathrm{Cl} / \mathrm{F}$, apparent oral-dose clearance (dose/AUC); $\mathrm{Cl}_{\mathrm{R}}$, renal clearance; $C_{\text {max }}$, peak plasma concentration; $\mathrm{CV}$, coefficient of variation; Geo. mean, geometric mean; $\mathrm{t}_{1 / 2}$, terminal-phase elimination half-life; $\mathrm{t}_{\max }$, time to $C_{\max }$

Table 2: Desvenlafaxine pharmacokinetic parameters for six age/sex cohorts plus statistical comparisons. 
Citation: Nichols Al, Richards LS, Behrle JA, Posener JA, Fruncillo R, et al. (2013) Effects of Age and Sex on the Pharmacokinetics, Safety, and Tolerability of Oral Desvenlafaxine in Healthy Adults. J Bioequiv Availab 5: 088-094. doi:10.4172/jbb.1000140

with age. There was an inverse relationship between the trend in $\mathrm{Cl}_{\mathrm{Cr}}$ and AUC values across age groups (Figure 2).

\section{Safety parameters}

Twenty-eight of 48 participants (58\%) reported AEs during the course of the study. Fewer participants receiving the 200-mg dose (47\%) reported AEs compared with those receiving the $300-\mathrm{mg}$ dose (100\%). No serious AEs occurred during the study. Treatment-emergent adverse events (TEAEs) were predominantly mild (84/92 [91\%]); no TEAEs were considered severe. Nausea (23\% of participants), dizziness (21\%), headache (17\%), and tachycardia (13\%) were the most frequently reported TEAEs. Nausea and dizziness were more common in women than in men. Nausea was reported more frequently in the young group (31\%) than the elderly (20\%) and very old (18\%) groups, while dizziness was reported more frequently in the elderly $(27 \%)$ and very old (24\%) groups than in the young group (13\%). Postural hypotension and vomiting were each reported by $8 \%$ of participants. Postural hypotension was more common in the elderly and very old groups, with no reports in the young group. To lessen the blood
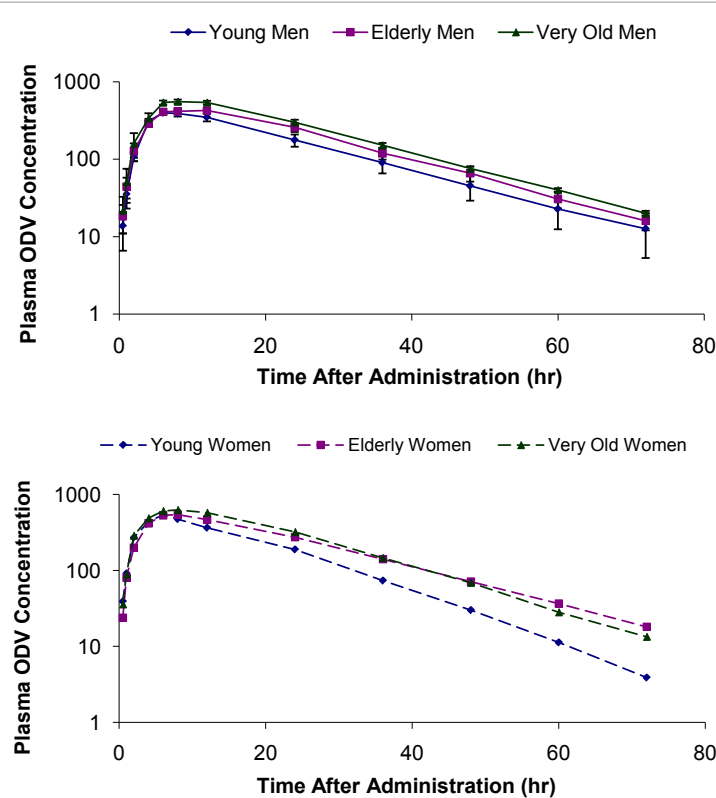

Figure 1: Dose-normalized plasma desvenlafaxine concentrations in healthy subjects receiving desvenlafaxine, mean values \pm s.e. ODV, O-desmethylvenlafaxine.

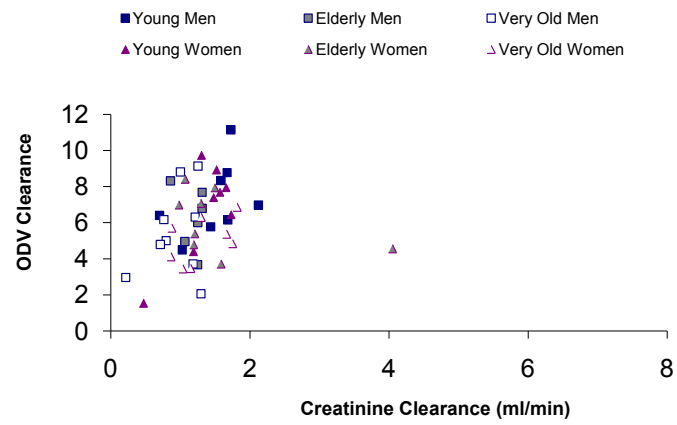

Figure 2: Creatinine clearance vs. ODV clearance. ODV, O-desmethylvenlafaxine. pressure and pulse rate responses, the dose was lowered from 300 to $200 \mathrm{mg}$.

\section{Discussion}

This open-label, single-dose study demonstrated small to moderate pharmacokinetic differences based on age and sex for desvenlafaxine studied here at four to six times the recommended dose. After oral, postprandial administration of 200 - or $300-\mathrm{mg}$ doses, desvenlafaxine was slowly absorbed in all age groups. However, desvenlafaxine exposure in women was greater than in men, and mean AUC values were approximately 1.55 -fold higher in very old male and female subjects compared with male and female participants in the youngest age group. This is consistent with observed decreases in $\mathrm{Cl} / \mathrm{F}$ in the elderly and in very old participants. The interaction of age and sex was not statistically significant for any of the parameters, indicating that the differences were attributable to differences between men and women or among age groups rather than changes in one cohort (e.g., women in the very old group).

Small to moderate pharmacokinetic differences were observed in men and women in this study. Within each age group, women exhibited a slightly shorter mean $\mathrm{t}_{\max }$ than men; women's mean $\mathrm{C}_{\max }$, $\mathrm{AUC}$, and weight-normalized $\mathrm{Cl} / \mathrm{F}$ exceeded those of men. These differences may be partially explained by lower body weight in women than men. Differences between men and women have also been observed in the pharmacokinetics of selective serotonin reuptake inhibitors and some of the atypical antidepressant drugs [22]. In a naturalistic study based on therapeutic drug monitoring samples in a clinical population, women had significantly lower citalopram clearance and significantly higher serum levels of citalopram and its catabolite, desmethylcitalopram, compared with men, across all age groups [23]. AUC was significantly decreased in young men ( $\leq 48$ or $<45$ years) compared with young women or elderly patients ( $\geq 65$ years) of either sex in multipledose sertraline [24,25] and single- and multiple-dose mirtazapine pharmacokinetic studies [25]. Sertraline $C_{\max }$ was lower, and $t_{1 / 2}$ was shorter, in young males compared with the other groups [24,25]. A significantly lower $\mathrm{C}_{\text {max }}$ for men compared with women (mean age, 24 years) has also been reported for single-dose reboxetine [26]. No elderly groups were included in that study. Higher steady state plasma concentrations of duloxetine were observed in women compared with men in a population pharmacokinetic analysis; no interaction with age was reported [27]. Sex differences in antidepressant pharmacokinetics are commonly attributed to differences between men and women in body weight or body composition [25,26,28], or to sex or hormone differences in antidepressant metabolism by cytochrome $\mathrm{P} 450$ isoenzymes [22,27].

Age-related changes were observed in several pharmacokinetic parameters, including significant changes in mean $A U C, C_{\max }$ and weight-normalized Cl/F. Desvenlafaxine exposure increased with age, with $C_{\max }$ increasing by $5 \%$ between young and elderly participants, and by approximately $32 \%$ between young participants and very old participants. Qualitatively similar findings were observed for AUC. Single-dose data from the 48 participants in this study indicated that mean AUCvalues normalized to the 200-mg dose of desvenlafaxine were $32 \%$ and $55 \%$ higher for elderly and very old participants, respectively, compared with young participants. These age-related changes are consistent with the observation that renal function decreases with age [14], and the dependence of desvenlafaxine elimination on renal function [29]. 
Age-related increases in exposure have been described for several other antidepressant drugs. Increased AUC, $C_{\text {max }}$, and $t_{1 / 2}$ were reported for elderly subjects compared with young subjects administered multiple-dose paroxetine [30] and single-dose nefazodone [31], and mirtazapine AUC was increased in elderly subjects compared with young adults [32]. Elderly women had a significantly reduced rate of clearance with single-dose duloxetine compared with young women [33], and reduced clearance and an increased $t_{1 / 2}$ was observed for reboxetine [33]. Citalopram steady-state pharmacokinetics were similar in young and elderly subjects, except that the elimination $t_{1 / 2}$ was significantly longer in the elderly [35]. Dose adjustments based on patient age are recommended for escitalopram [36]. A significant decrease in $\mathrm{CL} / \mathrm{F}$ with increasing age was observed in a population pharmacokinetic analysis: patients under 30 cleared escitalopram significantly faster compared with patients aged 30-50 years and greater than 50 years [37]. A significant decrease in clearance with increasing age was also observed in a population pharmacokinetic analysis of duloxetine [27], and in an analysis of therapeutic drug monitoring samples for citalopram [23]. In general, these differences have been attributed to age-related decline in hepatic or renal function [27,31-34]. In the current study, age-related differences may in large part be due to declining renal function. For example, the mean $\mathrm{Cl}_{\mathrm{R}}$ of desvenlafaxine decreased approximately $33 \%$ from the young to the very old group, and $\mathrm{Cl}_{\mathrm{R}}$ generally paralleled the decrease in $\mathrm{Cl}_{\mathrm{Cr}}$ with age, especially in the older age/sex cohorts. The relationship between age and declining renal function was further characterized by the fact that the age-related trend in mean $\mathrm{Cl}_{\mathrm{Cr}}$, a standard measure of renal function, was inversely related to mean AUC values.

The role of renal function can be explored further by calculating the $\mathrm{Cl}_{\mathrm{R}}$ from GFR (estimated by $\mathrm{Cl}_{\mathrm{Cr}}$ ), tubular secretion (TS), and tubular reabsorption (TA) $\left(\mathrm{Cl}_{\mathrm{R}}=\mathrm{GFR}+[\mathrm{TS}-\mathrm{TA}]\right)$. Because $\mathrm{Cl}_{\mathrm{R}}$ is similar to $\mathrm{Cl}_{\mathrm{Cr}}$, the tubular secretion must approximate $\mathrm{TA}$ in all age/sex groups. Thus, the reduction in mean $\mathrm{Cl}_{\mathrm{R}}$ of desvenlafaxine in very old participants can be largely attributed to the change in GFR.

Related observations can be made regarding the weight-normalized $\mathrm{Cl} / \mathrm{F}$ of desvenlafaxine. Mean $\mathrm{Cl} / \mathrm{F}$ was approximately $27 \%$ and $47 \%$ lower in the elderly and very old participants, respectively, than in young participants. The significant decrease in mean $\mathrm{Cl} / \mathrm{F}$ with increasing age translated into higher mean $\mathrm{AUC}$ and $\mathrm{C}_{\max }$ values for desvenlafaxine in very old participants compared with young participants. As with AUC, the change in mean $\mathrm{Cl} / \mathrm{F}$ (calculated as dose/AUC) can be at least partially explained by the age-related decrease in mean $\mathrm{Cl}_{\mathrm{R}}$ (which is closely related to mean $\mathrm{Cl}_{\mathrm{Cr}}$. . However, there was a broad range of $\mathrm{Cl}_{\mathrm{Cr}}$ values among age groups in both men and women. Consequently, the labeling for desvenlafaxine indicates no dose modification is necessary based on age alone, although decreases in renal function should be considered when selecting a dose regimen.

Analysis of safety data indicated that desvenlafaxine was associated with dose-related increases in mild to moderate TEAEs $(100 \%$ with 300-mg dose versus 47\% with 200-mg dose). Blood pressure responses, including orthostatic decreases or increases in supine blood pressure, occurred in the majority of very old and elderly participants who received a single $300-\mathrm{mg}$ dose of desvenlafaxine. Indeed, the study dose was reduced based on those results. Nausea, dizziness, headache, and tachycardia were the most common TEAEs in this study, but women reported more nausea and dizziness than men. Despite higher plasma concentrations of desvenlafaxine in the very old group, nausea was reported approximately twice as often in young participants, compared with participants in the very old group, and was $50 \%$ more common among young participants than among elderly participants. The higher desvenlafaxine dose $(300 \mathrm{mg})$, youth, and female sex appear to be associated with greater risk of nausea, although these results should be interpreted cautiously because of the small sample size in each age/ sex cohort. In addition, the doses assessed here were four to six times the recommended 50-mg/day dose, and thus the tolerability results for doses this high may not be relevant to clinical practice. An integrated analysis of data from short-term studies of desvenlafaxine for MDD demonstrated that doses of $200 \mathrm{mg} /$ day or higher were associated with poorer tolerability and no additional efficacy benefit compared with the 50-mg/day dose [19]. In that analysis, discontinuations due to AEs were dose-related, and did not differ from placebo for the $50-\mathrm{mg} /$ day dose group.

In summary, small to moderate differences in pharmacokinetics, not expected to be clinically relevant, were noted between men and women. As expected for a drug excreted primarily through the kidneys, exposure to desvenlafaxine increased with increasing age. No dose adjustment is considered necessary solely on the basis of sex or age. However, increases in AUC in participants aged $>75$ years warrant caution, and the possibility of reduced renal clearance of desvenlafaxine should be considered when determining dose for elderly patients. It is important to note that the labeling information for desvenlafaxine does not provide specific dosing information for elderly patients beyond the possibility of reduced renal clearance.

\section{Acknowledgments}

This study was sponsored by Wyeth Research, Collegeville, Pennsylvania, which was acquired by Pfizer in October 2009. Medical writing support was provided by Steven J. Cally, PhD, formerly of Advogent, Wayne, NJ, and Kathleen Dorries, PhD of Peloton Advantage, LLC, and was funded by Pfizer. Dr. Nichols, is an employee of Pfizer Inc. Ms. Richards, Ms. Behrle and Drs. Posener, Fruncillo, and Paul are former employees of Wyeth Research.

\section{References}

1. Deecher DC, Beyer CE, Johnston G, Bray J, Shah S, et al. (2006) Desvenlafaxine succinate: A new serotonin and norepinephrine reuptake inhibitor. J Pharmaco Exp Ther 318: 657-665.

2. Muth EA, Moyer JA, Haskins JT, Andree TH, Husbands GEM (1991) Biochemical, neurophysiological, and behavioral effects of Wy-45,233 and other identified metabolites of the antidepressant venlafaxine. Drug Dev Res 23: 191-199.

3. Pristiq (2011) Philadelphia, PA: Wyeth Pharmaceuticals, Inc, a subsidiary of Pfizer Inc.

4. Pfizer Pipeline as of February 28, 2011. www.pfizer.com. Accessed 3-3-2011.

5. Septien-Velez L, Pitrosky B, Padmanabhan SK, Germain JM, Tourian KA (2007) A randomized, double-blind, placebo-controlled trial of desvenlafaxine succinate in the treatment of major depressive disorder. Int Clin Psychopharmacol 22 338-347.

6. DeMartinis NA, Yeung PP, Entsuah R, Manley AL (2007) A double-blind placebo-controlled study of the efficacy and safety of desvenlafaxine succinate in the treatment of major depressive disorder. J Clin Psychiatry 68: 677-688.

7. Boyer P, Montgomery S, Lepola U, Germain JM, Brisard C, et al. (2008) Efficacy, safety, and tolerability of fixed-dose desvenlafaxine 50 and 100 $\mathrm{mg} /$ day for major depressive disorder in a placebo-controlled trial. Int Clin Psychopharmacol 23: 243-253.

8. Liebowitz MR, Manley AL, Padmanabhan SK, Ganguly R, Tummala R, et al. (2008) Efficacy, safety, and tolerability of desvenlafaxine $50 \mathrm{mg} /$ day and 100 $\mathrm{mg} /$ day in outpatients with major depressive disorder. Curr Med Res Opin 24 1877-1890.

9. Parks V, Patat A, Behrle J, Parker V, Decours J (2005) Safety, pharmacokinetics (PK) and pharmacodynamics (PD) of ascending single doses of desvenlafaxine (DVS-233 SR) in healthy subjects. Clin Pharmacol Ther 77: 28. 
Citation: Nichols Al, Richards LS, Behrle JA, Posener JA, Fruncillo R, et al. (2013) Effects of Age and Sex on the Pharmacokinetics, Safety, and Tolerability of Oral Desvenlafaxine in Healthy Adults. J Bioequiv Availab 5: 088-094. doi:10.4172/jbb.1000140

10. Richards LS, Behrle JA, Nichols Al, Fruncillo RJ, Paul J (2005) An ascending multiple-dose study of the safety and pharmacokinetics of a sustained-release formulation of desvenlafaxine succinate in healthy subjects. Clin Pharmaco Ther 77: 84.

11. Behrle JA, Nichols AI, McGrory SB, Raible D (2005) An open-label, randomized, single-dose, dose-proportionality study of oral doses of sustained-release formulation of desvenlafaxine succinate in healthy subjects. Clin Pharmaco Ther 77: P82.

12. Preskorn S, Patroneva A, Silman H, Jiang Q, Isler JA, et al. (2009) Comparison of the pharmacokinetics of venlafaxine extended release and desvenlafaxine in extensive and poor cytochrome P450 2D6 metabolizers. J Clin Psychopharmacol 29: 39-43.

13. Nichols AI, Behrle JA, Richards LS, Parker VD, Posener JA et al. (2012) The absolute bioavailability of desvenlafaxine in healthy subjects. J Bioequiv Availab 4: 018-023.

14. Danziger RS, Tobin JD, Becker LC, Lakatta EE, Fleg JL (1990) The ageassociated decline in glomerular filtration in healthy normotensive volunteers. Lack of relationship to cardiovascular performance. J Am Geriatr Soc 38: 11271132.

15. Levey AS, Coresh J, Balk E, Kausz AT, Levin A, et al. (2003) Nationa Kidney Foundation practice guidelines for chronic kidney disease: evaluation, classification, and stratification. Ann Intern Med 139: 137-147.

16. Papaioannou A, Ray JG, Ferko NC, Clarke JA, Campbell G, et al. (2001) Estimation of creatinine clearance in elderly persons in long-term care facilities. Am J Med 111: 569-573.

17. Rowe JW, Andres R, Tobin JD, Norris AH, Shock NW (1976) The effect of age on creatinine clearance in men: a cross-sectional and longitudinal study. $J$ Gerontol 31: 155-163.

18. Klamerus KJ, Parker VD, Rudolph RL, Derivan AT, Chiang ST (1996) Effects of age and gender on venlafaxine and O-desmethylvenlafaxine pharmacokinetics. Pharmacotherapy 16: 915-923.

19. Clayton AH, Kornstein SG, Rosas G, Guico-Pabia C, Tourian KA (2009) An integrated analysis of the safety and tolerability of desvenlafaxine compared with placebo in the treatment of major depressive disorder. CNS Spectr 14: 183-195

20. Thase ME, Kornstein SG, Germain JM, Jiang Q, Guico-Pabia C, et al. (2009) An integrated analysis of the efficacy of desvenlafaxine compared with placebo in patients with major depressive disorder. CNS Spectr 14: 144-154.

21. Cockcroft DW, Gault MH (1976) Prediction of creatinine clearance from serum creatinine. Nephron 16: 31-41.

22. Kokras N, Dalla C, Papadopoulou-Daifoti Z (2011) Sex differences in pharmacokinetics of antidepressants. Expert Opin Drug Metab Toxicol 7: 213226.
23. Reis M, Lundmark J, Bengtsson F (2003) Therapeutic drug monitoring of racemic citalopram: a 5-year experience in Sweden, 1992-1997. Ther Drug Monit 25: 183-191.

24. Warrington SJ (1991) Clinical implications of the pharmacology of sertraline. In Clin Psychopharmacol 2: 11-21.

25. Ronfeld RA, Tremaine LM, Wilner KD (1997) Pharmacokinetics of sertraline and its $\mathrm{N}$-demethyl metabolite in elderly and young male and female volunteers. Clin Pharmacokinet 32 Suppl 1: 22-30.

26. Fleishaker JC, Mucci M, Pellizzoni C, Poggesi I (1999) Absolute bioavailability of reboxetine enantiomers and effect of gender on pharmacokinetics. Biopharm Drug Dispos 20: 53-57.

27. Lobo ED, Quinlan T, O’Brien L, Knadler MP, Heathman M (2009) Population pharmacokinetics of orally administered duloxetine in patients: implications for dosing recommendation. Clin Pharmacokinet 48: 189-197.

28. Meibohm B, Beierle I, Derendorf H (2002) How important are gender differences in pharmacokinetics? Clin Pharmacokinet 41: 329-342.

29. Nichols AI, Richards LS, Behrle JA, Posener JA, McGrory SB, et al. (2011) The pharmacokinetics and safety of desvenlafaxine in subjects with chronic renal impairment. Int J Clin Pharmacol Ther 49: 3-13.

30. Kaye CM, Haddock RE, Langley PF, Mellows G, Tasker TC, et al. (1989) A review of the metabolism and pharmacokinetics of paroxetine in man. Acta Psychiatr Scand Suppl 350: 60-75.

31. Barbhaiya RH, Buch AB, Greene DS (1996) A study of the effect of age and gender on the pharmacokinetics of nefazodone after single and multiple doses. J Clin Psychopharmacol 16: 19-25.

32. Timmer CJ, Sitsen JM, Delbressine LP (2000) Clinical pharmacokinetics of mirtazapine. Clin Pharmacokinet 38: 461-474.

33. Skinner MH, Kuan HY, Skerjanec A, Seger ME, Heathman M, et al. (2004) Effect of age on the pharmacokinetics of duloxetine in women. $\mathrm{Br} \mathrm{J}$ Clin Pharmacol 57: 54-61.

34. Bergmann JF, Laneury JP, Duchene P, Fleishaker JC, Houin G, et al. (2000) Pharmacokinetics of reboxetine in healthy, elderly volunteers. Eur $\mathrm{J}$ Drug Metab Pharmacokinet 25: 195-198.

35. Gutierrez M, Abramowitz W (2000) Steady-state pharmacokinetics of citalopram in young and elderly subjects. Pharmacotherapy 20: 1441-1447.

36. Lexapro (2011) St. Louis, MO: Forest Pharmaceuticals, Inc, USA

37. Jin Y, Pollock BG, Frank E, Cassano GB, Rucci P, et al. (2010) Effect of age weight, and CYP2C19 genotype on escitalopram exposure. J Clin Pharmacol 50: $62-72$ 